\title{
A nova Guerra Fria de Hugo Chávez
}

Sergei A. Baburkin e Daniel Zirker

Após a Guerra Fria, potências intermediárias lutam para obter melhores posições em suas relações com os Estados Unidos e o sistema global. Analisando as relações triangulares entre Venezuela Rússia - Estados Unidos os autores detectam a persistência de elementos ideológicos e de segurança da Guerra Fria bem como a probabilidade de um retorno a práticas políticas dadas como superadas.

Palavras-chave: Guerra Fria, Políticas Globais, Governo de Chávez, Relações EUA-Rússia, Potências Intermediárias.

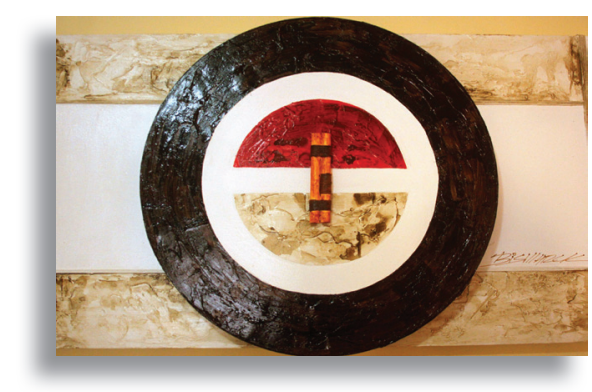

\section{The new Cold War of Hugo Chávez}

After the Cold War, middle powers struggled for better positions in their relations with the United States and the global system. Analyzing the triangular relations between Venezuela-Russia-United States, the authors detect the persistence of ideological elements and security of the Cold War as well as the likelihood of a return to outdated political practices.

Key words: Cold War, Global Politics, Chávez's Government, US-Russia Relations, Midlle Range Powers.

Sergei A. Baburkin: Professor da Yaroslavl State Pedagogical University, Rússia.

Daniel Zirker: Professor da University of Waikato, New Zealand. 


\section{INTRODUÇÃO}

Transcorreram duas décadas desde o fim da Guerra Fria. Atualmente o mundo é composto de potências intermediárias e candidatos a potências intermediárias dispostas, em muitos casos, a desafiar o ambíguo "sistema unimultipolar" (HUNTINGTON, 1999) emergido em sua sequência. Os EUA, em particular, têm mantido suas tendências intervencionistas na América Latina, um padrão que continua a desafiar uma nova geração de líderes latino-americanos. Mesmo onde a dominância sobre o comércio de exportações-chave como o petróleo foi atingida, a luta por encontrar um contraponto à hegemonia estadunidense é evidente. O crescimento nas relações comerciais com a China, ao mesmo tempo em que é promissor nesse aspecto, aparentemente ainda não foi capaz de se contrapor efetivamente à mistura de poder militar e financeiro que há muito caracteriza as políticas dos EUA na região.

Talvez não seja surpreendente que tentativas tenham sido feitas ao longo da década passada para ressuscitar elementos da Guerra Fria, primariamente no interesse de reviver "potências intermediárias" combativas, algumas das quais haviam se beneficiado marcadamente das suas alianças com uma ou outra das superpotências durante aquela era ideológica e antagônica. A Guerra Fria é sumarizada como um período no qual

A aliança entre a União Soviética e os Estados Unidos tinha se desgastado muito antes do fim da II Guerra Mundial. Potências rivais, eles se viram como defensores de ideologias antitéticas. Os Estados Unidos representavam os livres mercados e eleições livres contra a tirania coletiva do comunismo enquanto a União Soviética representava os interesses dos trabalhadores e outras pessoas que se sentiam exploradas pelo capitalismo, que entendia o que os estadunidenses celebravam como o "Mundo Livre" como um mundo que explorava a massa da humanidade para o benefício de um pequeno grupo majoritariamente composto por financistas e industriais estadunidenses. A desconfiança entre as duas nações, apenas levemente suavizada pelo reconhecimento pelos Estados Unidos da União de Repúblicas Socialistas Soviéticas nos anos 1930 e a aliança nos anos de guerra, explodiu sobre o futuro dos países do Leste europeu como a Polônia, nos quais regimes comunistas sob a influência direta de Moscou chegaram ao poder após o retorno da paz (ANDERSON; CAYTON, 2010, p. 396-397).

A América Latina também se tornou um campo de batalhas da Guerra Fria em virtude da lealdade daqueles que os EUA consideravam como seus aliados tradicionais. Nesta nação, a dominância tradicional de uma superpotência intervencionista foi, assim, mitigada ocasionalmente pelo conflito Oriente-Ocidente. Enquanto a vantagem das potências intermédias durante a Guerra Fria não deve ser exagerada, seu poder de 
barganha foi esporadicamente incrementado como aconteceu com Cuba após 1959, Peru, após 1968 e, talvez, o Chile, entre 1970-73.

A Guerra Fria levou a América Latina a experimentar uma das suas surpreendentemente homogêneas "ondas políticas" entre 1961 e 1989. Após o fim da Segunda Guerra Mundial, o aumento gradual dessa onda de autoritarismo logo ficou evidente. Neste contexto, o anticomunismo se tornou um ícone da política externa estadunidense, e particularmente após o sucesso da Revolução Cubana em 1959, os estabelecimentos militares latino-americanos se engajaram em uma prolongada série de intervenções autoritárias que redefiniram o papel do Estado e as regras das relações internacionais na região. O julgamento e a execução de uma série de graduados oficiais militares cubanos por Che Guevara quando era comandante da Prisão do Forte de La Cabaña imediatamente após o sucesso da Revolução Cubana deu aos militares latino-americanos razões para crer que o sucesso do "comunismo" significaria, literalmente, sua própria aniquilação. Entretanto, o número real de executados foi bastante exagerado, sobretudo por expatriados cubanos, mas o caso sem dúvida aumentou em grande medida a pressão psicológica dos argumentos ideológicos estadunidenses contra o comunismo nos estabelecimentos militares latino-americanos. O apoio e reconhecimento estadunidense a intervenções militares tipicamente garantiu seu êxito.

Alguns políticos proeminentes dos EUA tais como a embaixadora junto à ONU, Jeane Kirkpatrick, argumentaram que o autoritarismo era muito mais desejável que sistemas totalitários [leia-se: comunismo] porque os sistemas autoritários, esperava-se, durariam um período de tempo relativamente curto, enquanto os sistemas comunistas durariam para sempre. Deve-se notar de partida que novos paradigmas - nesse caso, o assim chamado sistema "unipolar/multipolar" do pós-Guerra Fria (HUNTINGTON, 1999) -, invariavelmente retêm elementos significativos do paradigma anterior. Contudo, nossa questão central envolve a persuasiva influência de Chávez sobre as políticas dos EUA e da Rússia em sua transparente tentativa de retornar a uma era mais tensa e conflituosa na qual os parceiros latino-americanos podiam esperar ser fortemente apoiados.

Não se pode esquecer o papel central da mídia durante a Guerra Fria. Apelar à mídia para ganhar um lugar na "agenda" tornou-se uma condição sine qua non do sucesso nas barganhas. Quando os mais pesados bombardeios na história do hemisfério ocidental (no meio dos anos 1980 durante a guerra civil em El Salvador) não foram noticiados nos principais jornais dos EUA e da Europa, a oposição perdeu seu poder de barganha. 
Do seu impacto na construção do Muro de Berlim, passando pelas reportagens da conduta estadunidense na Guerra do Vietnã, à moldagem do final da Guerra Fria com os relatos dramáticos da execução dos ceauescus e a queda do Muro de Berlim, imagens, ética, ideologia e poder de barganha foram em grande medida determinados pelas descrições midiáticas. Além disso, a habilidade de ambiciosas potências intermediárias na utilização da mídia para jogar as superpotências uma contra a outra, uma tática clássica de barganha em qualquer configuração de "balanço de forças", esteve evidente até o último momento da Guerra Fria.

O fim da Guerra Fria coincidiu com uma preocupação muito maior em relação às notícias na mídia. Como é notório, a influência potencial da mídia nos principais conflitos internacionais, tais como a mais recente guerra EUA-Iraque, veio a ser cuidadosamente limitada por políticas governamentais após o fim da Guerra Fria, embora com um sucesso relativo. James Hoge ressaltou em 1994 que a mídia tinha se tornado bem mais influente e insidiosa no período pós-Guerra Fria. Conforme observado por Hoge, "a televisão em 1962 estava tão subdesenvolvida que o secretário de Defesa [dos EUA] Robert McNamara não ligou nenhum aparelho de TV durante as duas semanas da crise [dos mísseis cubanos]". Hoge também notou, contudo, que

Essas capacidades da mídia moderna de ser imediata, sensacional e
predominante são inquietantes para a conduta das relações interna-
cionais. Isto seria assim mesmo que a Guerra Fria continuasse ativa,
mas no desdobramento amorfo de uma rivalidade bem definida entre
as superpotências o impacto da instantaneidade da mídia se intensifica
(HOGE, 1994, p. 137).

Evidentemente a ativação de tensões de uma nova Guerra Fria, com vistas a serem bem-sucedidas, dependeria uma vez mais do condicionamento das percepções populares globais e particularmente daquelas nas antigas superpotências, os EUA e a Rússia, através de reportagens midiáticas. Ao estabelecer a agenda e familiarizar as populações com personagens-chave e posições políticas, a mídia, nesse sentido, funcionou ao mesmo tempo como um estímulo e um indicador. Ao ativar a consciência popular e intensificá-la, foi fundamental ao componente de luta da Guerra Fria. O fracasso de alguma tentativa de construir tais antagonismos no dia de hoje, além disso, representaria a perda daquela vantagem.

Não se deve subestimar os desafios latentes na busca pela reintrodução das tensões do balanço de poder do passado. As relações têm sido cordiais, embora ainda dolorosamente formais, entre as antigas superpotências globais, Rússia e EUA, desde 1991. Contudo, segundo se 
depreende, as relações entre os EUA e muitas das potências intermediárias no mundo inteiro e particularmente na América Latina têm sido irregulares na melhor das hipóteses. O poder de barganha baseado em lealdades e compromissos mutantes manifestos durante a Guerra Fria já não existe. Formalmente, a mídia central a essa barganha entre "coalizões ideológicas" antagônicas está, ironicamente, mais cuidadosamente controlada. Potências intermediárias dias que antes podiam "comandar" poder e recursos bem além das suas capacidades lógicas, mesmo aquelas tão visíveis quanto Egito, Israel, Cuba e Índia, agora lutam pelo mais mínimo apoio desse tipo.

Em suma, no ambiente pós-Guerra Fria, nenhuma potência intermediária tem sido capaz até o momento de ressuscitar suficientes elementos da Guerra Fria para se tornar beneficiária da massiva infusão de recursos que os aliados da Guerra Fria rotineiramente recebiam apesar de vários países, sobretudo na Europa Oriental, terem tentado conseguir esse jogo imaginário de dois estágios: a ressurreição de argumento ideológicos e intensamente armados da Guerra Fria e sua inserção neles como elementos de estabilidade. Em continuidade, exploram-se as tentativas de impactar a política global por um desses líderes latino-americanos, Hugo Chávez, da Venezuela.

Parece que se alguém pode ser capaz de retormar elementos da Guerra Fria mediante estratégias cuidadosamente elaboradas para elevar os níveis de antagonismo entre Rússia e Estados Unidos, esse alguém seria Hugo Chávez. Seus esforços, apoiados por significativos recursos petroleiros,são claros. Teriam suas políticas e abordagem estimulado um retorno a elementos da Guerra Fria?

\section{HUGO CHÁVEZ E A GUERRA FRIA}

Embora não esteja no escopo deste artigo explorar em detalhes a biografia e história política de Hugo Chávez, cabe mencionar resumidamente alguns pontos-chave. ${ }^{1}$ Chávez é talvez um dos mais carismáticos políticos na história recente da América Latina, se não do mundo, e tem obtido altos índices de aprovação popular na Venezuela. Ele tem, de fato, consolidado estes índices ao longo da última década e obteve uma aprovação de 71,5\% no final de 2006 (KOZLOFF, 2007), apoio que tem se mantido em grande medida intacto. Como observou Pew Research Institute em 2009:

1 Ver, a esse respeito, Gott (2005) e sobre Simón Bolívar, Lynch (2007). 
Em 2007, a maioria dos venezuelanos não apenas tinha visões positivas sobre as habilidades em política exterior de Chávez, mas também uma visão positiva de seu impacto geral no país. Em 2007, seis em cada dez [venezuelanos] disseram que Chávez tinha uma boa influência sobre a maneira como as coisas iam no país, enquanto 38\% disseram que ele era uma má influência. Novamente, venezuelanos de baixa renda e escolaridade tinham mais probabilidade de apresentar opiniões positivas sobre o impacto do presidente no país. Contudo, pesquisas mais recentes indicam que as visões sobre Chávez têm se tornado mais críticas na Venezuela. Por exemplo, uma pesquisa conduzida de maio a junho de 2008 pela empresa venezuelana Alfredo Keller y Asociados (AKSA) indicou que 47\% tinham uma opinião positiva sobre Chávez, caindo de 59\% um ano antes e 64\% em 2006. Apesar de a maioria das pesquisas de opinião respeitadas terem mostrado o referendo passando por uma pequena margem, algumas pesquisas recentes sugeriram que ele poderia fracassar. Enquanto Chávez mais uma vez confundiu os céticos, sua reivindicação de liderança regional aparentaria ter pouco apoio na vizinhança (PEW RESEARCH, 2009).

Seu estilo muitas vezes lembra o dos populistas dos anos 1960 e 1970, como nota um observador:

O projeto político de Chávez tem sido uma mistura eclética de populismo, nacionalismo, militarismo e, mais recentemente, socialismo, combinado com uma ênfase "bolivariana" na unidade sul-americana. Chávez se vê como a encarnação da vontade popular, a "democracia participativa", focalizada no empoderamento e mobilização dos venezuelanos, é a essência do Chavismo (SHIFTER, 2006).

Neste âmbito, o programa semanal do presidente Chávez na TV, "Aló, Presidente", é virtualmente único na política. Ele organizou esse programa dominical de discussão política por temas de modo que qualquer espectador pode telefonar e discutir problemas diretamente com o presidente.

Como evidenciado, o foco central da Revolução Bolivariana que Hugo Chávez tenta implementar são os conceitos bolivarianos de autarquia, o uso do petróleo como "arma geopolítica" e desafios diretos à hegemonia econômica dos EUA na Venezuela e na América Latina. Enquanto o poder econômico dos EUA na região se reduziu significativamente na década passada, as circunstâncias especiais da Venezuela como fornecedora-chave de petróleo a um sedento mercado estadunidense precisam ser consideradas. Petróleos de Venezuela (PDVSA), a estatal petrolífera venezuelana, havia gradualmente evoluído em uma instituição semiprivada em 1999. Chávez reconheceu que a crise econômica de larga escala venezuelana, na qual a classe média havia sido quase extinta, se devia em grande medida ao "saqueio" dos recursos naturais, incluindo o petróleo, por corporações multinacionais associadas a importantes 
executivos da PDVSA. Demandas neoliberais impostas à Venezuela após os anos 1980, pagamentos de empréstimos, reestruturação, estabilização de preços, etc. fomentaram um "inimigo" bastante claro e reconhecível. Ademais, o saqueio dos recursos naturais tinha tido impacto sobre a opinião pública venezuelana.

Chávez foi capaz de ativar um movimento nacional revolucionário a partir da presidência definindo a identidade dos seus inimigos e ao mesmo tempo consolidando a dos seus seguidores. Seu objetivo aparente, contudo, parece ser muito maior: atrair o apoio e a influência de grandes poderes estrangeiros, incluindo China e Irã, e acionar um retorno a um tipo de conflito polar e ideológico como a Guerra Fria que pudesse mais uma vez obter o apoio da Rússia para uma descontente república sul-americana.

Filho de pais pobres, Chávez nasceu em uma pequena vila da região de Llanos no Estado de Barinas em 1954, durante a era do brutal ditador general Marcos Pérez Jiménez, e foi criado por sua avó Rosa. Ele foi morar com sua avó por causa das dificuldades financeiras dos seus pais para cuidar de seis crianças. Cresceu em um lar rígido e bastante pobre e manteve forte ligação com sua avó, que lhe mostrou a importância da história e do herói revolucionário do século XIX Ezequiel Zamora, a quem Chávez veio a idolatrar segundo se diz (JONES, 2007). Em 1971, aos 17 anos, foi aprovado na entrevista de admissão e começou seus estudos na academia militar nacional. Conforme Jones, baseado em entrevistas com Chávez, um bem-sucedido teste para o time de beisebol da academia foi decisivo para sua admissão (JONES, 2007). Fascinado com a história de Simón Bolívar, "sua fascinação transformou-se em uma devoção profunda que chegava perto da obsessão" (JONES, 2007, p. 40). Através de uma viagem acadêmica ao Peru em 1974, Chávez familiarizou-se com a ditadura militar de esquerda de Juan Velasco Alvarado e seu "Plano Inca", um experimento social progressista liderado pelos militares destinado a corrigir os problemas da desigualdade e pobreza. Por volta de 1975, ano da sua graduação na academia militar, Chávez estava se radicalizando. Como comentaria mais tarde, "nós estudávamos táticas antiguerrilha, mas eu já estava questionando tudo" (JONES, 2007, p. 54).

Após sua graduação e designação como comandante antiguerrilha, a desilusão de Chávez se intensificou, culminando em uma série de encontros clandestinos com o líder guerrilheiro Douglas Bravo. No começo dos anos 1980, Chávez havia criado uma célula militar clandestina, EBR-200, com uma vaga visão de mundo bolivariana. Quando Carlos Andrés Pérez retornou à presidência em 1989 com uma agenda neoliberal disfarçada 
e especialmente após sua ordem para que os militares suprimissem a revolta resultante, ganhou a inimizade incondicional de Chávez. A corrupção de Pérez foi a gota de água. Chávez dirigiu um fracassado golpe militar contra Pérez em 1992 e passou dois anos na prisão, durante os quais Pérez sofreu impeachment e foi destituído do cargo por corrupção. Chávez saiu da prisão ainda mais comprometido com a oposição ao neoliberalismo e à política das elites. Sua eleição à presidência em 1998 parece ter representado a culminação lógica de uma carreira dedicada tanto à liberação americana quanto à mudança e ele logo voltou suas atenções à construção de alianças internacionais.

A Aliança Bolivariana das Américas (Alianza Bolivariana para los Pueblos de Nuestra América, ou ALBA) representou uma crescente "coalizão" internacional de neossocialistas com ideias afins, incluindo Chávez, Evo Morales, da Bolívia, Rafael Correa, do Equador e Daniel Ortega, da Nicarágua, e levou vários anos para emergir. Esses países são membros da carta da ALBA e vistos como uma ampla coalizão nas linhas do Mercosul, prestes a incluir uma aliança econômica na qual a moeda universal será o sucre, e não o dólar estadunidense. A lista completa de membros da ALBA inclui Antigua e Barbuda, Bolívia, Cuba, Dominica, Equador, Nicarágua, São Vicente e Granadinas e Venezuela. Esses líderes apoiadores não estavam no cargo em 2005, quando apenas Venezuela, Cuba e Síria votaram contra uma resolução da Agência Internacional de Energia Atômica para enviar a demanda iraniana por energia nuclear para exame pelo Conselho de Segurança da ONU (SHIFTER, 2006). A crescente aliança de Chávez compartilha uma oposição natural ao Consenso de Washington, o projeto neoliberal para a região com as maiores disparidades de renda no mundo (JONES, 2007).

Chávez gasta uma boa parcela de energia e recursos no fortalecimento da ALBA, embora, mesmo assumida coletivamente, seu controle sobre recursos e táticas seja bastante limitado. Para fortalecer significativamente sua posição Chávez precisaria encontrar um nicho no ambiente global. Isto demandaria em última instância encontrar um sistema mais amplo que valorasse e recompensasse suas visões. Enquanto vários cenários possíveis poderiam satisfazer essa demanda, incluindo laços mais fortes com a China, uma tática potencialmente mais barata, a atração do apoio russo e um consequente fortalecimento da sua posição de barganha diante dos EUA, parece ter chamado sua atenção primeiro. A implementação dessa tática tem aparentemente envolvido Chávez em uma tentativa de ressuscitar alguns dos mais proeminentes elementos da Guerra Fria. Considerando que a Venezuela se encontra atualmente 
cercada por instalações militares estadunidenses, com os EUA atuando como provocador, essa seria uma estratégia natural.

A Guerra Fria é um tema potencialmente ilimitado, e uma história substantiva do seu caráter e dinâmicas fogem ao escopo desse artigo. Várias das suas características-chave, no entanto, são pertinentes, sobretudo na medida em que se relacionam com os dilemas do desenvolvimento venezuelano. Primeiro, a Guerra Fria dependia vitalmente de um balanço de poder entre duas superpotências, os EUA, e a União Soviética. Em muitos sentidos, esse balanço representava um empate. Contudo, no referente às constantes tentativas de atrair outros países a um campo ou outro, a Guerra Fria provou ser uma vantagem para potências intermediárias. Assistência estrangeira e mesmo a partilha parcial de poder facilmente seguiam as tentativas dos EUA e URSS de atrair adeptos. Além disso, o revestimento ideológico das políticas da Guerra Fria - capitalismo versus socialismo - somava um tipo de justificação moral às tentativas de criar coalizões globais. Assim, retórica e discurso, elementos-chave às políticas da América Latina, tornaram-se elementos centrais da política da Guerra Fria.

Nesse sentido, o uso consciencioso de Chávez da retórica da Guerra Fria e o estabelecimento de posições políticas internacionais provocativas sugerem um desenho fundamental. Muito se disse, por exemplo, do alojamento por Chávez de dois bombardeiros estratégicos de longo alcance russo em uma base venezuelana em setembro de 2008, quando ele declarou que "a hegemonia ianque está acabada" (BBC, 2008). Como evidenciado, a posição de Chávez carrega certas ambiguidades. Por exemplo, o uso de petróleo como arma estratégica e o estabelecimento de coalizões com países como o Irã podem minar em alguma medida a estratégia ideológica mais ampla de coalizão com a Rússia.

Após 1990, novos e significativos desafios surgiram para as potências intermediárias. Como notado por Huntington conforme sua perspectiva ultraconservadora, na era pós-Guerra Fria muitas potências intermediárias tornaram-se adversárias naturais do que ele chama de "xerife solitário" em referência aos Estados Unidos (1999). Pressionado a responder a desafios estadunidenses diretos à soberania venezuelana, Hugo Chávez escolheu uma resposta mais limitada de resistência e promessa. A nosso ver, ela é bem interessante porque nos revela elementos da dinâmica das políticas internacionais contemporâneas. 


\section{CHÁVEZ E A REAÇÃO DOS EUA}

Chávez tem sido razoavelmente bem-sucedido em provocar uma "resposta do tipo Guerra Fria" nos EUA. Os elementos-chave dessa resposta, argumentamos, deveriam seguir os padrões históricos da Guerra Fria na política estadunidense diante da América Latina. Entre estes, por exemplo, o apoio a grupos anticomunistas e sistemas autoritários, preocupação extrema em relação a ameaças à "livre empresa" e particularmente o fluxo contínuo de recursos estratégicos aos EUA, vários esforços ativos e passivos de desestabilização de governos adversários, espionagem, apoio significativo a opositores eleitorais e a várias diversas formas de resistência autoritária aos governos de esquerda, incluindo apoio secreto a tentativas de golpes militares. G. W. Bush e, em menor grau, Barack Obama, ao que parece, sucumbiram ocasionalmente a respostas do tipo Guerra Fria a Chávez. Michal Shifter, em artigo na revista Foreign Affairs em 2006, afirmou:

Infelizmente, a atitude prevalecente em relação a Chávez em Washington parece presa em uma era diferente - ela representa uma estrutura mental reminiscente da Guerra Fria, quando a América Latina se tornou um feroz campo de batalhas entre os Estados Unidos e a União Soviética. Desde que Chávez chegou ao poder, Washington tem estado confuso sobre como lidar com ele. Suas mensagens - às vezes conciliatórias, às vezes confrontadoras, às vezes contraditórias - têm sido em grande medida reativas e mostram pouco no sentido de um pensamento estratégico (SHIFTER, 2006).

Desse ponto de vista, o governo Bush era propenso a reações da Guerra Fria mesmo na ausência de condições objetivas. O presidente Obama, ao tempo em que tenta reduzir as tensões em seus contatos diretos com o presidente Chávez, também tem escorregado em retóricas da Guerra Fria ocasionalmente.

De qualquer forma, revive a estrutura mental estadunidense da Guerra Fria. Por exemplo, o anticomunismo, a reprodução da política exterior russa e a ameaça iminente de guerra nuclear e destruição global, têm sido severamente complicados pela mudança de paradigma global. A nova oposição "ideológica" defendida pelos EUA ao longo das últimas duas décadas tem representado uma fusão entre religião, cultura e ideologia frequentemente parafraseada, não importa o quão erroneamente, como "terrorismo". Este pode ser o maior desafio ao governo de G. W. Bush: uma inclinação natural a se opor a qualquer ameaça à "livre empresa" e aos interesses financeiros imediatos dos EUA como "comunistas" (a resposta da Guerra Fria) tinha agora de ser transformada em última 
instância em uma "ameaça terrorista" se quisesse esperar qualquer resposta mais definitiva do Congresso. Chávez correspondeu em alguma medida, aparentemente, ao estabelecer supostas relações próximas com um grupo guerrilheiro colombiano, as Forças Armadas Revolucionárias da Colômbia (FARC), ao fortalecer os laços do seu país com o Irã, identificado pelo Departamento de Estado do governo Bush como apoiador do terrorismo e por uma longa série de estridentes declarações antiestadunidenses enfatizando, e talvez conscientemente confundindo, os temas do terrorismo e do capitalismo. Isso foi meticulosamente difundido pelos representantes mais direitistas da imprensa estadunidense. A Fox News, por exemplo, mantém uma longa lista algo contraditória de comentários antiestadunidenses de Chávez (chamado pela imprensa dos EUA de "antiamericano") em seu sítio web, a maioria deles destinados a avivar a Guerra Fria em políticos reacionários. Como alguns dos comentários de Chávez sobre os EUA revelam, o imperialismo estadunidense e a retórica da Guerra Fria são fundidos e encontram-se na linha de frente da sua política. Em 2009 a Fox News, a mais direitista da majoritariamente conservadora imprensa estadunidense, descreveu e se referiu aos comentários de Chávez da seguinte forma, chamando abertamente de anticomunistas extremistas frequentemente descritos como semifascistas, a exemplo de Otto Reich:

- Os EUA bombardearam cidades inteiras, usaram armas químicas e napalm, mataram mulheres, crianças e milhares de soldados. Isso é terrorismo (25/9/2005: entrevista ao Washington Post).- O governo dos EUA sob Bush é o "mais selvagem, cruel e assassino império que já existiu na história do mundo" (8/8/2005: comício com juventude em Caracas).

- Nosso verdadeiro inimigo chama-se império estadunidense e no domingo, 2 de dezembro, vamos dar outro nocaute em Bush para que ninguém esqueça que esse é um campo de batalha (1/12/2007: discurso eleitoral em Caracas).

- A política estadunidense no Oriente Médio é uma "política de agressão permanente, de guerra, de terrorismo do império estadunidense. Esse é o verdadeiro culpado, o grande Satã, como eles chamam aqui (1/4/2009: Teerã, Irã).

- A atitude imperialista, genocida, fascista do presidente dos EUA não tem limites. Eu acho que Hitler seria bebê chorão ao lado de George W. Bush (4/2/2004: comício em Caracas).

- Os EUA e seus aliados são culpados de disparar "fogo imperialista! Fogo fascista! Fogo assassino! [...] fogo genocida contra o povo inocente da Palestina e do Líbano pelo Império e Israel" (durante discurso na ONU em setembro de 2006).

- O eixo do mal é Washington e seus aliados ao redor do mundo, que saem ameaçando, invadindo e assassinando. Nós [Chávez e o presidente boliviano Evo Morales] estamos formando o eixo do bem (3/1/2005: Caracas). 
- Os EUA provocaram os ataques (11/9) sobre si mesmos com sua política externa imperialista arrogante (12/9/2001: TV venezuelana).

- A hipótese que está ganhando força [...] é que foi o mesmo poder imperial dos EUA que planejou e executou esse ataque ou ato terrorista terrível contra seu próprio povo e contra os cidadãos de todo o mundo. Por quê? Para justificar as agressões que foram imediatamente dirigidas contra o Afeganistão e o Iraque (12/9/2006: discurso em Caracas). - "O demônio veio aqui ontem", disse Chávez na Assembleia Geral da ONU, referindo-se ao presidente Bush, ao fazer o sinal da cruz, e acusou os EUA de "dominação, exploração e pilhagem dos povos do mundo" (20/9/2006: Nova York).

- Eu espero estar errado, mas acredito que Obama traz o mesmo fedor que o presidente Bush (17/1/2009: discurso em Caracas).

- Eles estão ameaçando qualquer país que decida ser livre (1/2/2007: discurso em Caracas).

Enquanto esse tipo de palavras traria as adagas do Serviço Secreto sobre a maioria dos ofensores, valeram a Chávez uma forte saudação e agradecimentos de Obama, que também recebeu um presente de Chávez no encontro de 34 países na Cúpula das Américas em Porto Espanha, Trinidad.

No domingo, Obama justificou o aperto de mãos e disse que sua presença na cúpula ajudaria a desobstruir as relações com outras nações das Américas.

“É pouco provável que como consequência de eu apertar as mãos ou ter uma conversa educada com o Sr. Chávez estejamos ameaçando os interesses estratégicos dos Estados Unidos", afirmou Obama.

Mas alguns diplomatas veteranos disseram que Chávez usaria aquele gesto como um importante símbolo para ajudar a consolidar seu crescente poder na Venezuela.

"O que ele dirá é que o que ele tem feito na Venezuela agora tem o selo de aprovação dos Estados Unidos", disse Otto Reich, que foi embaixador na Venezuela durante a presidência de Ronald Reagan. "Ele o vê como um sinal verde para seguir desmantelando a democracia na Venezuela".

Reich disse que Chávez já está usando o aperto de mãos como propaganda e chamou a cúpula de oportunidade desperdiçada por Obama.

"O que o presidente dos Estados Unidos ontem à noite e hoje está tentando como um aperto de mãos, Chávez já está anunciando como o maior exito - sucesso - na história política venezuelana", disse ele (Fox News, 2009).

A Fox News tem claramente enfatizado os elementos da Guerra Fria na retórica de Chávez, se é que não o está ajudando conscientemente a obter o apoio da Rússia ao invocar a hostilidade da Guerra Fria.

Como evidenciado, a administração Bush reagiu fortemente ao primeiro governo Chávez, ressuscitando na maior parte, se não em todas, as táticas adotadas na América Latina durante a Guerra Fria, entre estas, 
de destituí-lo por meio de um golpe de Estado. A tentativa de golpe contra Chávez em 2002, que aparentemente ameaçou sua vida, foi logo (e desastradamente, ante a imediata resposta dos EUA) endossada pelo governo Bush. O fracasso subsequente do golpe em seguida a uma ampla demonstração de apoio à democracia constitucional na Venezuela provou-se um profundo embaraço ao governo dos EUA. Além disso, mostrou o relativamente frágil apoio dos EUA aos conspiradores.

Em uma era de apoios a democracias de vários tipos, onde o governo Clinton tinha, apenas alguns anos antes, ajudado diretamente a abortar várias tentativas de golpe no Paraguai, Bush parecia incapaz de apelar a táticas da Guerra Fria apesar da sua preferência óbvia. Como Chávez ressaltou após o golpe:

Agora seu governo rompeu realmente todos os protocolos democráticos de respeito pelo povo. O golpe de Estado contra a Venezuela foi manufaturado em Washington. Minha morte foi encomendada. E foi encomendada recentemente (KOZLOFF, 2007, p.2).

Contudo, o governo Bush tinha pouco apoio popular dentro dos EUA em suas políticas reativas a Chávez. Ele não parecia estar incentivando nenhum ressentimento nos EUA ou sequer, talvez, interesse. Um retorno a intervenções estilo Guerra Fria era aparentemente impossível para Bush.

Operações secretas estadunidenses na Venezuela foram, tadavia, significativamente aumentadas sobretudo após o fracassado golpe de 2002. Como marcos fundamentais das políticas da Guerra Fria, operações secretas - espionagem, sabotagem, apoio discreto a oposição autoritária - sempre tenderam a envolver um marco institucional especificamente desenhado para a Guerra Fria. Golinger (2008) examina diversas acusações de casos de espionagem dos EUA na Venezuela, incluindo acusações que levaram à expulsão do capitão John Correa, adido militar dos EUA, e indícios ligando o tenente coronel Humberto Rodriguez, adido do Exército dos EUA, e o tenente coronel da Força Aérea Bernard Lewis a espionagem. Os EUA consideraram essas acusações e a expulsão como provocações, no estilo da Guerra Fria. Por conseguinte, enquanto a Agência de Informações dos EUA, um ícone fundamental dos anos à Guerra Fria, fora extinta em 1999, outras agências, entre estas, o National Endowment for Democracy, ainda existiam e foram rapidamente modificadas para lidar com a "situação venezuelana" (KOZLOFF, 2007, p.2).

Uma das mais pronunciadas, apesar de discreta, respostas imediatas no estilo Guerra Fria do governo de G. W. Bush ao governo Chávez foi a extensão do projeto "American Corners", originalmente desenvolvido pelo 
Departamento de Estado dos EUA nos anos 1990 para implementação na Rússia. Esse projeto buscava "preservar os avanços e o trabalho feitos durante a Guerra Fria e continuar uma presença de baixo perfil para garantir que a propaganda e informação dos EUA ainda fossem efetivas" (GOLINGER, 2008, p.143). Seus modus operandi era implantar "consulados" informais em sistemas potencialmente adversativos mediante criação de "postos consulares" não oficiais que tendiam a ser fundados pelo Departamento de Estado dos EUA "em uma nação sem a autorização do governo hospedeiro" (GOLINGER, 2008, p.143). Como afirma Golinger, "a ideia [do projeto Corners] é criar um tipo de 'consulado satélite' não formalmente ligado ao governo dos EUA, mas sim a uma organização local, associação, escola, biblioteca ou instituição" (2008, p.143). A estrutura de apoio do projeto Corners, dos quais se especula a existência de mais de duzentos ao redor do mundo, especialmente na Europa Oriental e Ásia Central, parece mais próxima da Guerra Fria que do período após seu término. De acordo com Eva Golinger,

Em 2006, o embaixador [dos EUA na Venezuela] William Brownfield inaugurou quatro American Corners na Venezuela nas cidades de Barquisimeto, Margarita, Maturín e Lecherías, no estado de Anzoátegui. Os Corners em Barquisimeto, Margarita e Maturín são sediados em associações regionais de advogados, incluindo o Colegio de Abogados (Ordem dos Advogados) no estado de Lara, que também recebe financiamento do National Endowment for Democracy. No caso de Lecherías, no estado de Anzoátegui, o Corner está localizado nos escritórios do governo municipal, que é governado por um prefeito oposicionista. De acordo com a embaixada estadunidense na Venezuela, "a função do American Corner em Lecherías é ser um centro de estudos e informação. O Corner oferece livros escritos por uma grande variedade de autores estadunidenses e acesso grátis à internet para indivíduos locais interessados em aprender. Ele divulga notícias atualizadas sobre os Estados Unidos e também organiza eventos e atividades com foco na cultura estadunidense. A tarefa fundamental do American Corner é proporcionar ao público em geral acesso à informação sobre os Estados Unidos da América" (GOLINGER, 2008, p. 144).

O leitor é levado a uma comparação com o conflituoso papel da Agência de Informação dos EUA (USIA, na sigla em inglês), interrompida em 1999; no período da Guerra Fria, a agência no exterior tinha outro nome, Serviço de Informações dos EUA, aparentemente uma atrapalhada tentativa de evitar a comparação da sua sigla com a da Agência Central de Inteligência dos EUA (CIA).

As crescentes evidências da abordagem do governo Obama perante Chávez e a Venezuela sugerem o início de uma profunda mudança da reação da presidência de G. W. Bush e dessa forma um fracasso relativo 
de Chávez na elevação da sua posição global por meio da reativação das políticas da Guerra Fria. Ante a oposição inicial do presidente Barack Obama ao golpe militar em Honduras em 2009, que pareceu deixar Chávez surpreso, seu sorriso cordial e o aperto de mãos com Chávez na Cúpula das Américas em abril de 2008 e seu convite a este para se engajarem em um diálogo construtivo, todos apontam para a modificação de uma resposta puramente reacionária ao estilo Guerra Fria que Chávez rotineiramente evocava de George W. Bush. Isto foi celebrado pelos adversários de Chávez como um golpe contra suas políticas provocativas.

A avaliação de inteligência dos EUA elaborada pelo ex-diretor de Inteligência Nacional dos EUA, Dennis Blair, antes de ser demitido pelo presidente Obama em maio de 2010 por insubordinação, descrevia a situação na América Latina como complexa, mas longe de pessimista. Em seu relatório oficial intitulado "América Latina estável, mas ameaçada por crime e populismo", ele nota que:

A governança democrática permanece forte na América Latina e no Caribe onde uma vasta maioria de países está comprometida com a democracia representativa, liberalização econômica e relações positivas com os Estados Unidos. Em alguns países, contudo, a democracia e políticas de mercado permanecem em risco em virtude de contínuas ameaças do crime, corrupção e má governança. Na maioria dos Estados, problemas econômicos sérios têm agregado estresse adicional às instituições democráticas (BLAIR, 2010, p.30).

Contra esse pano de fundo, então, alguns países, apenas um destes considerado uma "potência intermediária", são aparentemente considerados pelos EUA como "problemáticos". Além disso, essa visão elitista de ameaça é expressa em termos convenientemente quase humanitários:

Em outros países como Venezuela, Bolívia e Nicarágua, líderes populistas eleitos estão direcionando um modelo político e econômico mais autoritário e estatista e têm se unido para se opor à influência e às políticas estadunidenses na região (BLAIR, 2010, p. 30).

O relatório prossegue dizendo que Hugo Chávez é considerado o líder desse grupo: "O presidente venezuelano Hugo Chávez se estabeleceu como um dos mais destacados detratores internacionais dos EUA, denunciando a democracia liberal e o capitalismo de mercado e se opondo às políticas e interesses estadunidenses na região" (BLAIR, 2010, p. 30). Em um relatório de 2009, Blair notara que "Chávez tem dado especial atenção nos meses recentes ao aprofundamento dos laços políticos, econômicos e militares com a Rússia" (BLAIR, 2009, p. 32). Blair continuou esse tema em seu relatório de 2010, prevendo que "Chávez continuará a cultivar laços políticos, econômicos e de segurança mais próximos com Irã, Rússia e 
China" (BLAIR, 2010, p. 33). E nas sombras da Guerra Fria, Blair concluiu que "a Rússia continua a usar suas forças armadas em um esforço para afirmar seu status de grande potência e projetar seu poder no estrangeiro[...]" (BLAIR, 2010, p. 30). A reação da elite política estadunidense, então, parece ter sido atraída para uma resposta à la Guerra Fria, embora em grau menor. No entanto, o interessante contraste se dá com a opinião popular estadunidense que parece não estar nem um pouco preocupada com um retorno à Guerra Fria.

\section{CHÁVEZ E A REAÇÃo RUSSA}

Como seria vista na ótica russa uma tentativa de Hugo Chávez de ressuscitar ao menos alguns elementos da Guerra Fria? Tal apelo teria de convencer líderes-chave como Vladimir Putin da necessidade de assumir consideráveis riscos internacionais em favor de uma aliança com a Venezuela. Além disso, eles teriam de reativar forte consciência popular de Chávez e da Venezuela numa perspectiva da Guerra Fria que incluísse uma ênfase no nacionalismo russo, em contrastes ideológicos (especialmente a natureza perversa do capitalismo) e em um senso de solidariedade internacional entre as nações oprimidas do mundo.

Talvez de igual relevância fosse a oferta de significativos benefícios econômicos, provavelmente sob a forma de compra de armas ou transferência tecnológica ou mesmo a partilha de recursos importantes. Porém, o mais marcante, contudo, no contexto da democratização russa, seria uma alta visibilidade de Chávez e da Venezuela na consciência russa suficiente para reverter a crescente tendência da Rússia em focar suas políticas na europeização e recuperação financeira, conforme evidenciado nas diretivas políticas expressas por Putin (PUTIN, 2007). Chávez, então, teria de capturar a imaginação e o apoio do povo russo através da mídia. No mínimo, o povo russo teria de conhecer Hugo Chávez e a Venezuela.

Ao longo da última década, as atividades de Chávez atraíram a atenção da mídia russa e, em menor escala, da sua opinião pública, e de forma plausível provocaram um discurso intenso, apesar de contraditório, no âmbito das elites. Em seu centro está o decisivo processo de mudanças políticas na Venezuela, sobretudo ligado a Chávez e aos passos políticos por ele tomados, bem como a seus discursos e declarações frequentes. Em seu discurso o presidente venezuelano busca, em grande medida, propiciar materiais novos para discussão e, periodicamente, focalizar a mídia russa e, em decorrência, a atenção nacional sobre política venezuelana e o próprio Chávez. Contudo, talvez, seu impacto mais forte 
sobre as matérias na mídia russa envolvam a habilidade de Chávez em periodicamente relacionar os eventos venezuelanos a assuntos internacionais e, ainda mais significativamente, direcionar a mídia mundial para a Venezuela. Nesse contexto são recuperados argumentos centrais da Guerra Fria.

É impossível não reconhecer que Chávez tenta angariar o apoio popular russo. Ele foi o primeiro líder latino-americano a visitar a Rússia após a eleição de Putin à presidência. Desde então, esteve na Rússia outras quatro vezes e se mantém bastante ativo em aproveitar as oportunidades para abordar temas de significância para a liderança e a opinião pública russas e, aparentemente, causar uma boa impressão. A abordagem pessoal e elogiosa de Chávez tem sido conscientemente manifesta. Desde seu primeiro encontro com Vladimir Putin, no qual de forma pomposa se colocou em posição de karatê para honrar a faixa preta que Putin detém nessa arte marcial (JONES, 2007), ele tem adotado um comportamento entusiasmado e de apoio ao líder russo. Entre os assuntos abordados por Chávez durante suas visitas constam questões de justiça social, ligações históricas entre os dois países e uma aparentemente sincera admiração pelos feitos históricos do povo russo em suas lutas contra seus muitos invasores e inimigos ao longo dos últimos séculos. Subjacente a isto jaz o assunto mais central da solidariedade internacional na luta contra o estabelecimento de um capitalismo predatório e a "ordem mundial" pósGuerra Fria.

Um ponto significante na retórica de Chávez é a manifestação de sua simpatia pessoal por Putin e sua consideração por esta amizade. Além disso, ele frequentemente menciona o povo russo e Putin como aliados em uma luta mútua contra um inimigo comum, os EUA, ligando seus comentários a críticas diretas àquele país, que ele tende a retratar como o centro de um império imoral e agressivo, uma completa antítese à Rússia. A narrativa de Chávez traz uma marcante e consistente semelhança com a retórica da Guerra Fria: ele continuamente identifica a Rússia como um aliado em seu discurso anti-imperialista, identifica pontos de oposição entre a Rússia e os EUA e apresenta a Rússia e a Venezuela como aliados próximos em uma luta mútua. Por exemplo, em sua chegada em 2006 a Izhevsk, a cidade onde a submetralhadora "Kalashnikov" é produzida, Chávez disse: "Os EUA são o império mais imoral e cínico. Eu agradeço à Rússia e ao meu amigo Putin por seu apoio. Nós precisamos de armas 
apenas para a autodefesa. Em caso de agressão, nós defenderemos a Venezuela como vocês defenderam Stalingrado". ${ }^{2}$

Talvez não seja surpreendente que à medida que a aquisição de tecnologia militar aumenta em importância durante suas visitas à Rússia, também tem crescido sua retórica anti-imperialista. Ele enfatiza a esse respeito a importância da venda de armas russas, bem como outras formas de cooperação militar, para a proteção da soberania da Venezuela contra futuras ações secretas ou ataques abertos por parte do imperialismo estadunidense. "Se não fora pela Rússia nós nos encontraríamos sem armas. Dessa forma é necessário reconhecer a coragem do governo russo que não cedeu às pressões do império". ${ }^{3}$

Tanto a impressão que Chávez produz na sociedade russa quanto a resposta que ele obtém das suas atividades e apelos são ambíguas. Russos de esquerda veem Chávez como o "sucessor de Fidel", para eles um renomado líder do anti-imperialismo, "um homem verdadeiro", alguém firme o suficiente para lutar contra os EUA. O associam a ele em suas esperanças de um renascimento dos movimentos socialista e comunista. Com efeito, seu apoio a Chávez vai bastante além da ressurreição da Guerra Fria; aparentemente ele desafia a autoridade dos líderes russos atuais. Chávez, na visão da esquerda russa, é "um líder da revolução socialista pelo qual estivemos esperando tanto tempo" e "um mensageiro da futura vitória do socialismo no mundo inteiro". Como a "esperança da humanidade progressista", ele "lidera uma luta sagrada contra o imperialismo mundial". Os mais radicais expressam não apenas esses sentimentos, mas também repetidamente juram seu apoio a Chávez e sua causa: "Se for necessário, tomaremos armas e defenderemos Hugo Chávez e sua ilha de liberdade". ${ }^{4}$ Um observador que participou de uma das palestras de Chávez em Moscou assim se pronunciou:

Hugo Chávez impressionou Moscou, uma incomum, mas não esquecida por aqui, combinação de retórica revolucionária e o status de líder de Estado. À primeira vista, um personagem como Hugo Chávez poderia ser percebido em nossa cena política como uma figura absolutamente marginal - um populista, um idealista romântico, expressando a si mesmo em retórica cubano-soviética. Contudo, a ovação recebi da de intelectuais russos pelo presidente da Venezuela no Instituto de

2 http://www.kp.ru/daily/23746/55622/

3 http://news.mail.ru/politics/1365948/

4 http://peoples.ru/state/king/venezuela/Chávez/forum.shtml 
Filosofia da Academia Russa de Ciências mostra como o círculo daqueles ansiosos por ver o retorno dos valores de justiça social na política tem se expandido na Rússia [...] o presidente conseguiu tocar [...] uma veia nostálgica da intelligentsia da capital (russa) que pode ser ouvida em seu inspirador discurso; temas familiares à era soviética a respeito do imperialismo mundial, a agressividade dos EUA, revolução e seu cuidado para com os trabalhadores[...] (POLITICHESKII JURNAL, 2004).

A esquerda russa obviamente espera que com a unidade e fortalecimento de Cuba, Venezuela e "alguns outros países progressistas" o papel dos EUA como bastião do imperialismo decline e esse processo seja irreversível. Eles veem o mundo dividido em três campos - os EUA e seus aliados, a oposição a eles e aqueles ainda indecisos e que eventualmente se unirão ao lado vencedor, um cenário bem parecido com o da Guerra Fria. Nessa perspectiva, uma Venezuela com forças renovadas e "liderança esclarecida" tornar-se-ia um fator central na unificação dos adversários dos EUA (PEOPLES, 2006).

Para intelectuais russos de esquerda, Chávez é uma figura mais simpática que Putin e frequentemente comparam os dois. Um deles afirma: "Eu não esqueço do seu [Chávez] encontro com Putin. Chávez é um tipo forte, aberto, ativo, com um sorriso hollywoodiano. E o nosso [Putin] - sentando de lado e olhando para o chão - é um semijudoca. É uma vergonha!". ${ }^{5}$ Ao mesmo tempo, a política da Venezuela em relação aos Estados Unidos parece mais decisiva e decente que o caminho russo: "Infelizmente, Chávez é quase o único homem que não se ajoelha ao gendarme mundial". 6

Os Bolcheviques Nacionais Russos (membros e apoiadores do Natsional-Bolshevitskaya Partia, Partido Nacional-Bolchevique (PNB), uma organização radical não oficialmente registrada no Ministério da Justiça), um grupo bastante propenso a aderir pela esquerda a mensagens pró-Guerra Fria, acham que "Hugo Chávez [é] quase como um verdadeiro 'natsbol' [e] toma conta da segurança de seu país e seu povo". Para eles, é um sinal positivo que "diferentemente de Putin, ele (Chávez) não serviu nos serviços especiais" (NAZLOBU, 2006).

Para os patriotas russos, dessa forma, Chávez, "a tempestade da Venezuela", figura na companhia de heróis mundiais, líderes capazes de conduzir suas nações em tempos de crise. Ele está, para eles,

5 http://peoples.ru/state/king/venezuela/Chávez/forum.shtml(ANATOLII, 22/9/2006 8:52:11).

6 http://peoples.ru/state/king/venezuela/Chávez/forum.shtml(JACOBO, 24/7/2006 16:30:55). 
ressuscitando a memória, se não a realidade, da Guerra Fria. É visto pelos nacionalistas como uma figura que legitimamente busca seu lugar "no panteão mundial dos líderes fervorosos, ao lado de Gandhi, Martin Luther King Jr., Arafat, Castro e Stálin" (PROKHANOV, 2004). Novamente, a ligação com a ideologia da Guerra Fria fica clara. Contudo, é notoriamente superficial associar tão fortemente antiamericanismo e ideologia da Guerra Fria. Evidentemente, Chávez satisfaz as expectativas antiamericanistas russas. Como um partidário escreveu, "Chávez é um sujeito legal apenas porque persegue políticas anti-EUA. Se for boa para seu povo, que ele governe pelo resto da sua vida". Outros, mais céticos e práticos, hesitam diante dos instintos socialistas de Chávez. Um deles afirma:

Chávez não é bobo! Mas no longo prazo ele não chegará à vitória. A Venezuela durante os anos soviéticos vivia melhor do que nós, de acordo com dados da ONU. Algum dia o petróleo acabará. Outras abordagens são necessárias. Ele não é socialista do mesmo modo que os chineses também não são. Ele usa as contradições entre as duas grandes potências para o bem do seu próprio país. Ele é uma farsa e um demagogo, mas não é bobo. ${ }^{7}$

Ao mesmo tempo, as pessoas à direita do cenário político russo menosprezam o mito do progresso da política socialista de Chávez:

O país é pobre e apenas na capital é possível viver mais ou menos [bem]. Em muitas províncias as pessoas vivem apenas da subsistência e não têm dinheiro[...] Eu aconselho aos camaradas que apoiam Chávez a ir lá e viver ao menos um ano por conta própria[...] As pessoas estão escrevendo [sobre a Venezuela] sem conhecer a situação. Existe socialismo somente para aqueles ligados ao petróleo [e Chávez é um deles e para uma elite de burocratas.

Alguns dos oponentes ideológicos de Chávez na Rússia generalizam: "Sob o manto vermelho há apenas merda para o povo. Fome, devastação, ditadura - esse é o destino da Venezuela". ${ }^{8}$ Outros temem que "nossos tolos façam a mesma besteira aqui". ${ }^{9}$

Comentários no fórum de internet mail.ru sobre o referendo de dezembro de 2007 na Venezuela refletem todo o espectro de opiniões e pontos de vista que emergiram na sociedade russa nos anos anteriores a respeito da política de Chávez. Contudo, vale a pena notar que o fiasco de Chávez no

7 http://news.mail.ru/politics/1473942/comments/?page=2

8 http://news.mail.ru/politics/1473942/comments/?page=2 5/11/2007 12:11

9 http://news.mail.ru/politics/1473942/comments/?page=2 
referendo de 2 de dezembro de 2007 foi percebido por alguns observadores russos com um tipo de satisfação, se não uma total falta de entusiasmo da Guerra Fria. O vice-presidente do Comitê de Relações Internacionais da Câmara Alta do Parlamento Russo, Vasilii Likhachev, disse que a sociedade venezuelana mostrou sua "alta cultura política e responsabilidade" ao não apoiar as reformas constitucionais do presidente Chávez. Ainda como enfatizou, "a liderança do país vê os resultados do referendo como um fato político objetivo" que lhe permite interpretar o que ocorre no país como "um diálogo entre autoridades e sociedade". A experiência venezuelana deveria atrair a atenção de analistas e políticos em muitos países, pois "o slogan 'escute a sociedade, escute o povo' continua a ser importante". Ele também notou de forma interessante que "democracias controladas têm seus limites. E a liderança deveria prevê-los e senti-los. De outra forma, pode haver o risco de uma crise na democracia, uma crise de poder e a perda de toda a esperança pela população" (IZVESTIA, 2007b).

As principais pesquisas de opinião russas apontam para atitudes profundamente contraditórias a respeito de Chávez e, ao mesmo tempo, mostram a magnitude, ou a falta dela, do seu impacto na opinião pública russa. Apesar de ter aparecido com frequência na televisão russa ao longo dos últimos anos, uma maioria de russos não estão familiarizados com ele. Apenas 19\% em uma pesquisa recente responderam corretamente à pergunta "quem é o presidente da Venezuela". Ademais, 74\% admitiram não saber o nome do presidente venezuelano e outros 7\% disseram outros nomes ao ser perguntados. Isto deve ser visto contextualmente: a Rússia tem uma população letrada que regularmente assiste a noticiários televisivos. De fato, após serem informados de que o líder da Venezuela é Hugo Chávez foram perguntados se tinham visto tal pessoa na TV, lido sobre ele em jornais, escutado sobre ele no rádio, e em caso afirmativo, qual sua impressão sobre ele. Como resultado, 70\% dessa amostra aleatoriamente selecionada da população russa não tinham ouvido ou lido nada a respeito de Chávez e não tinham visto programas de TV sobre eventos venezuelanos ou internacionais com os quais Chávez tivesse estado envolvido. Outros $18 \%$ de respondentes afirmaram ter uma impressão positiva de Chávez, e apenas $4 \%$ uma impressão negativa. Os demais pesquisados acharam difícil responder. Àqueles que tiveram alguma impressão de Hugo Chávez foi pedido que o caracterizassem. Conforme as respostas, os russos que tinham alguma simpatia pelo presidente da Venezuela o consideravam um "político direto, firme, progressista, decidido, forte e independente" e um "homem alegre, gentil, charmoso e 
bonito" e tendem a mencionar sua proximidade com o povo. Alguns resaltaram como fato positivo que ele "resiste aos EUA" e a G. W. Bush e Barack Obama pessoalmente e que é amigo de Fidel e Raúl Castro e um "aliado da Rússia". Outros o caracterizaram como "revolucionário" e "um ardente comunista". Aqueles que demonstraram uma atitude negativa em relação a Hugo Chávez tenderam a descrevê-lo como um "ditador, fascista, palhaço, falador, muito impulsivo, louco, imprudente, agressivo" e ressaltaram que "um político deveria ser mais correto". ${ }^{10}$

Esses resultados de pesquisa são semelhantes aos resultados regionais de Chávez na América Latina. Apesar de os latino-americanos tenderem a conhecê-lo, sua confiança nele é decididamente baixa, como exposto pelo Pew Research (2011):

A pesquisa de Atitudes Globais Pew encontra pouca confiança em que Chávez fará a coisa certa na política mundial. Entre os países latino-americanos pesquisados, pouco menos de um em cinco disseram ter confiança na habilidade de Chávez como líder global no Brasil (17\%), México (17\%), Peru (15\%) e Chile (14\%). Mesmo no país liderado por um dos mais próximos aliados de Chávez - a Bolívia de Evo Morales - apenas um terço expressou confiança no líder venezuelano. Opiniões acerca de Chávez foram mais variadas na Argentina, onde quase tantos expressaram confiança quanto a falta dela (40\% versus $43 \%$ respectivamente). Entre 2007 e 2008, a confiança em Chávez declinou em todos os três países latino-americanos incluídos na pesquisa de Atitudes Globais - Argentina, Brasil e México. No Brasil a queda foi menos substantiva, de $17 \%$ para $12 \%$. Contudo, na Argentina, apenas um quarto (26\%) mantinha muita ou alguma confiança em Chávez em 2008, uma queda de 14 pontos percentuais em comparação com 2007. Similarmente no México, os índices de confiança em Chávez declinaram 11 pontos percentuais, de $17 \%$ para $6 \%$.

A pesquisa regional de 2011 do Latinobarómetro (Chile) com uma amostra de 19 mil latino-americanos trouxe esses resultados:

Os países cujos presidentes são de direita são os países com a pior opinião sobre Hugo Chávez. Na Colômbia e no México [o apoio] alcança somente $14 \%$. Nove dos dezoito países da região têm uma opinião abaixo da média regional (33\%). As opiniões sobre e a respeito da Venezuela estão empapadas de ideologia. Ela é julgada a partir da posição de cada um na escala na escala esquerda - direita (LATINOBARÓMETRO, 2011).

A cooperação militar com a Rússia tem assumido o centro do discurso no tocante aos aspectos internacionais da política de Chávez. De acordo com o Izvestia, entre 2005 e 2007 a Venezuela assinou contratos para a compra de 25 aeronaves, 50

10 http://bd.fom.ru/report/cat/frontier/zarubezhnye_politiki/chaves/d063927/ 
helicópteros e 100 mil submetralhadoras ao custo total de US\$ 4,3 bilhões (IZVESTIA, 2007a). Frequentemente os EUA têm questionado o suprimento de armas russas à Venezuela, embora de maneira cuidadosa, sugerindo sutilmente que a Rússia deveria pensar duas vezes antes de abastecer a Venezuela. Ademais ressalta: é o governo russo que tem de tomar sua própria decisão a esse respeito. Nas palavras do representante do Departamento de Estado, Shawn McCormack, "a decisão sobre a venda de armas deve ser feita pelo governo russo. Nós gostaríamos de explicar nosso ponto de vista a esse respeito ao governo russo antes que qualquer compra seja concluída". Sua insinuação era de que as compras planejadas de armamentos superavam as necessidades da Venezuela.

Para as autoridades russas, o tema da cooperação técnica com a Venezuela constitui um objetivo importante. Ao mesmo tempo, elas não enfatizam implicações antiestadunidenses desses acordos e tendem a discutir o assunto em termos puramente econômicos enquanto destacam outros aspectos das relações russo-venezuelanas. Especialistas russos hoje consideram as relações da Rússia com a Venezuela como um sinal da ressurreição econômica da Rússia, seu retorno a uma presença no hemisfério ocidental e as vendas de armas como canal de influência sobre a OPEP. Eles concordam em que a "Rússia não se concentre em velhas amizades geopolíticas e esteja diversificando sua política externa em uma região como a América Latina" utilizando todos os métodos para encontrar novos parceiros econômicos e melhorar sua liquidez. Conforme um observador da Academia Russa de Ciências, Sergei Kazenov, nota:

Do ponto de vista da utilização da Venezuela como uma carta na manga nas relações com os Estados Unidos - não se pode superestimá-lo. E a Venezuela não conseguirá muito da Rússia. Mas hoje há um jogo de cartas mútuo sendo jogado e se a Rússia é levada em consideração nesse jogo, esse é um bom sinal (TSUNSKII, 2001).

Pareceria, segundo a perspectiva russa, então, que é Chávez/ Venezuela, e não a Rússia, quem está desempenhando um papel ativo na provocação aos EUA e na tentativa de trazer a Rússia para o seu lado em um novo ambiente global semelhante à Guerra Fria. Contudo, os líderes russos parecem estar tentando preservar e melhorar as relações com os EUA, ainda que ao mesmo tempo manifestando uma disposição em utilizar algumas das oportunidades que se apresentam em suas relações com a Venezuela para conter, de maneira passiva, a influência dos EUA na América Latina, especialmente nas amplas áreas de comércio, cooperação técnico-militar e petroquímica. 
Se Hugo Chávez em suas declarações enfatiza aspectos militares e estratégicos das relações russo-venezuelanas, a liderança russa explicitamente se limita a admitir apenas as mútuas vantagens das relações comerciais e econômicas. Com efeito, parecem existir esforços russos para acalmar e minimizar as implicações antiestadunidenses dos contatos russo-venezuelanos, como evidenciado no rebaixamento do status diplomático da quarta visita de Chávez à Rússia por ocasião da Cúpula do G-8 em São Petersburgo em junho de 2006.

Após as eleições de 2008, as relações Venezuela-Rússia não tiveram qualquer mudança significativa. Pelo contrário, elas mostraram continuidade e ascendência ao longo das linhas traçadas anteriormente, tanto no plano simbólico quanto no prático. A cooperação militar foi expandida, e a cooperação econômica no setor de energia fortalecida. Visitas, entre estas a primeira oficial de um chefe de Estado russo à Venezuela, estiveram em destaque na mídia russa. Um número significativo de novos acordos entre Venezuela e Rússia foi assinado. Apoio venezuelano declarado à Rússia após a guerra com a Geórgia pela Ossétia do Sul e apoio à independência desta e da Ingushetia caracterizaram o sentido da "aliança" e apoio acrítico oferecido por Chávez à Rússia.

Tudo isso foi acompanhado por uma retórica de diferentes tons. Da parte de Chávez, houve ênfase na cooperação semimilitar e mesmo a um tratado para explicitamente conter o poder estadunidense na América Latina. Da parte de Medvedev, em contraste, tem se mantido um tom amigável em suas respostas, e se evitado uma clara retórica anti-EUA, bem como uma abertura a acordos pragmáticos, incluindo a cooperação em assuntos militares.

Chávez não alterou seu apelo lisonjeiro à liderança russa: "Eu li seus discursos e compartilho totalmente da sua posição, em especial sobre a política para o Oriente Médio, onde você demonstra a multipolaridade", ressaltou Chávez em uma mensagem ao presidente Medvedev durante seu primeiro encontro em julho de 2008 (ILLIN; SEDEBE, 2008). Em uma linguagem que envolvia alguns dos principais temas da Guerra Fria, Chávez enfatizou publicamente a Medvedev durante sua visita a Moscou em setembro de 2009: "Você é meu amigo e camarada agora, Dimitry. [...]. A Rússia está firme sobre seus pés e a Venezuela é um dos núcleos do que será o polo de poder na América do Sul" (GABUIEV, 2009).

As respostas dos líderes russos a essas propostas de Guerra Fria têm sido moderadas, neutras ou mesmo de contenção. Apesar de Chávez continuar a insistir que a principal ameaça à Venezuela são os EUA, os líderes 
russos evitam concordar abertamente. Por exemplo, durante sua visita à Venezuela em novembro de 2008, Medvedev afirmou que a "cooperação técnica militar [da Rússia à Venezuela] não está dirigida contra quaisquer Estados" (KUZMIN, 2008).

A grande mídia russa "séria" tende a tratar a retórica de Chávez com uma dose saudável de ironia. Um exemplo típico desta foi exibida em Kommersant:

O líder venezuelano sempre precisou de uma linguagem de inimigo externo, cujo papel sempre é desempenhado pelos EUA. Com a queda nos preços do petróleo, que desproveu o orçamento venezuelano de recursos para inúmeros projetos sociais que apoiavam a popularidade de Hugo Chávez junto ao estrato mais pobre da população, a consolidação da nação em face da conspiração secreta do 'império', parece, se torna ainda mais urgente (PORTIAKOVA, 2009).

O comentário do Kommersant seguia e mencionava as renovadas acusações de Chávez segundo as quais os EUA sob Obama não tinham mudado em relação aos anos de Bush.

\section{CONCLUSÕES}

O triângulo político EUA-Venezuela-Rússia tem ressoado ao longo da última década em meio à publicidade e iniciativas diplomáticas. Contudo, fica claro que o presidente Chávez tem obtido apenas um sucesso limitado na contribuição ao restabelecimento das estruturas antagônicas de ideologia e poder da Guerra Fria, sua intenção aparente. Apesar de algumas respostas reacionárias dos governos de G. W. Bush, Barack Obama, Vladimir Putin e Dmitry Medvedev terem resultado dos frequentemente impressionantes desafios políticos de Chávez, várias das respostas por ele obtidas tanto dos EUA quanto da Rússia mostram as profundas dificuldades latentes em qualquer tentativa de retomar o antigo paradigma. Mais importante, talvez, a persistente influência da mídia na política pós-Guerra Fria não engrandeceu de forma significativa os desafios de Chávez. No tocante aos EUA, a despeito dos desmedidos esforços dos direitistas nas gestões de Bush e Obama, o governo somente foi capaz de oferecer apoio passivo à tentativa de golpe contra Chávez e aparentemente conteve suas resistências mesmo à notável aproximação entre Chávez e o presidente Mahmoud Ahmadinejad do Irã. As reações irregulares de Obama tampouco obtiveram maior impacto. A Fox News as tem retratado como indicativo da sua ingenuidade ou concessões aos inimigos dos EUA, como no caso do famoso aperto de mãos 
entre Obama e Chávez na Cúpula Latina em abril de 2009, reportando a resposta defensiva (e significativa) subsequente de Obama à mídia: "É pouco provável que como consequência de eu apertar as mãos ou ter uma conversa educada com o Sr. Chávez estejamos ameaçando os interesses estratégicos dos Estados Unidos" (apud REUTERS, 2009). Os cidadãos estadunidenses têm apenas ocasionalmente, e de maneira bastante moderada, se indignado com Chávez e em grande medida quase desconhecem sua existência. Ademais, o presidente Barack Obama tem agido decisivamente para minar as invectivas de Chávez contra os EUA. No inerente à Rússia, o presidente e mais tarde primeiro-ministro Putin tem recebido Chávez cordialmente, mas parece manter-se sensível ao relativo desinteresse público dos russos e mesmo sua total ignorância a respeito do presidente Chávez. As relações de negócios com o país, incluindo comércio de armas, contrastam com as frequentes aproximações de Putin com a Europa e sua rejeição fundamental ao "terrorismo" e, dessa foram, à boa-vontade de Chávez em dialogar com "todos os lados".

Talvez o maior potencial de Chávez nessa relação triangular seja forjar um bloco de apoiadores entre os líderes de esquerda na América Latina. Nesse esforço, ele tem obtido um sucesso relativo. Além das ligações com Cuba e os irmãos Fidel e Raúl Castro, ele tem atraído para si o apoio entusiasta de Evo Morales, da Bolívia, Rafael Correa, do Equador, Daniel Ortega, da Nicarágua (todos unidos à ALBA) e, talvez, de modo ainda mais notável tendo em vista a resposta diplomática inconstante de Obama a um golpe de Estado, do ex-presidente de Honduras, Manuel Zelaya. Além disso, vem trabalhando de maneira próxima com esquerdistas mais moderados como o ex-presidente Luiz Inácio Lula da Silva, do Brasil, Michelle Bachelet, do Chile, os Kirchners, na Argentina e outros. Estaríamos, então, obsevando a emergência de uma nova "Guerra Fria multipolar"? Parece improvável. As relações têm mudado dramaticamente no triângulo político EUA-Venezuela-Rússia, mas as mudanças parecem ser mais o produto do fim da Guerra Fria do que algum tipo de retorno a ela, mesmo com todos os esforços feitos por Chávez.

Apesar de o personalismo ser frequentemente identificado como um elemento fundamental da política nacional na América Latina, o triângulo político EUA-Venezuela-Rússia mostra em alguma medida os limites de um indivíduo carismático em reviver elementos da Guerra Fria. Chávez claramente tem tido alguma influência no ressurgimento de sentimentos da Guerra Fria, contudo, o mundo tem aparentemente seguido adiante. Chávez é talvez um dos mais dinâmicos, carismáticos e efetivos líderes 
nacionais na história mundial, mas ele é, no fim das contas, apenas uma pessoa. Como nosso estudo tentou demonstrar, os esforços de Chávez têm se confrontado com o que agora parece ser um vasto momento histórico distante das políticas de "equilíbrio de poder", da mobilização ideológica de populações e das profundas disputas ideológicas entre povo e elite do período da Guerra Fria. Os resultados das aproximações carismáticas, criativas e eficientes de Chávez com a Rússia e suas similarmente efetivas tentativas de arrastar os EUA para um conflito global oferecem provas de que a Guerra Fria está finalmente e irrevogavelmente morta. Como Marx argumentou significativamente no "18 Brumário": "Os homens fazem sua própria história, mas não a fazem segundo sua vontade; eles não a fazem em circunstâncias por eles escolhidas, mas sob circunstâncias determinadas transmitidas pelo passado" (MARX, 1972, p. 437).

Traduzido do inglês por

Clayton M. Cunha Filho e Mônica Dias Martins

\section{REFERÊNCIAS}

ANDERSON, F.; ANDREW, C. The dominion of war; empire and liberty in North America 1500-2000. New York: Viking Press, 2010.

BBC.com. Russian bombers land in Venezuela. (11 Sep. 2008): http://news.bbc. co.uk/2/hi/americas/7609577.stm.

BLAIR, D. C. Relatório do Diretor de Inteligência Nacional. Annual Threat

Assessment of the US Intelligence Community, para o Comitê de Inteligência do Senado, 2 de fevereiro, 2010.

Relatório do Diretor de Inteligência Nacional, Annual Threat

Assessment of the US Intelligence Community, para o Comitê de Inteligência do Senado, 12 de fevereiro, 2009.

FOX NEWS. Handshake With Obama Belies Chavez's Contempt for America. http://www.foxnews.com/politics/first100days/2009/04/20/concerns-brewingobamas-warm-embrace-chavez/ Acesso em: 30 de jun./2009.

GABUIEV, A. A Cândida admissão." Kommersant, Sept 11. (Габуев.

Чистосердечное признание. Коммерсантъ, 11 сентября 2009.) http://www.

kommersant.ru/doc.aspx?DocsID $=1235617 \&$ ThemesID $=368$

GOLINGER, E. Bush vs Chávez: Washington's War on Venezuela. NY: Monthly Review Press, 2008.

The Chávez Code; Cracking US Intervention in Venezuela.

Northampton, Massachusetts, USA: Olive Branch Press, 2006.

GOTT, R. The Bolivarian Revolution in Venezuela. London: Verso, 2005. 
HAWKINS, K. A. Who Mobilizes? Participatory Democracy in Chávez's Bolivarian Revolution. Latin American Politics and Society, v. 52,

n. 3. p. 31-66, 2010.

HOGE, J. Media Pervasiveness. Foreign Affairs, v. 73, n. 4, p. 136-144, jul./ ago. 1994.

HUNTINGTON, S. P. The Lonely Superpower. Foreign Affairs, v. 78, n. 2, mar./ abr. 1999.

ILLIN, A.; SEDEBE, P. O Enviado de Caracas. Dmitri Medvedev se encontra com Hugo Chávez. Rossiiskaya Gazeta (Russian Newspaper), 23 de julho de 2008. (Алексей Ильин, Пьер Сидибе, Посланец Каракаса. Дмитрий Медведев встретился с Уго Чавесом.) “Российская газета”, 23 июля 2008.http://www. rg.ru/2008/07/23/chaves.html.

IZVESTIA. Hugo Chávez está viciado em comprar tecnologia militar russa (27 fev. 2007a) (Уго Чавес пристрастился к покупке военной техники в Росси.): http:// www.finiz.ru/cfin/tmpl-art_news/id_art-1158714 O fracasso de Hugo Chávez revela a democracia na Venezuela (3 dez. 2007b). ( Провал Уго Чавеса “обнаружил" в Венесуэле демократию.): http://www. izvestia.ru/news/news156290

JONES, B. iHugo! The Hugo Chavez story from mud hut to perpetual revolution. Hanover, New Hampshire, USA: Steerforth Press, 2007.

KOZLOFF, N. Hugo Chávez; Oil, politics, and the challenge to the US. NY: Palgrave Macmillan, 2007.

KUZMIN, V. Ao Amigo Chávez". Rossiiskaya Gazeta, 28 de nov. 2008. (Владимир Кузьмин. К другу Чавесу. "Российская газета”, 28 ноября 2008: http://www.rg.ru/2008/11/28/medvedev-chavez.html

LATINOBARÓMETRO. La Imagen de Venezuela.(1º fev. 2011): http://www. latinobarometro.org/latino/latinobarometro.jsp .

LUPU, N. Who Votes for Chavismo? Class Voting in Hugo Chávez's Venezuela. Latin American Research Review, v. 45, n. 1, p. 7-32, 2010.

LYNCH, J. Simón Bolívar: A Life. New Haven: Yale University Press, 2007.

MARX, K. The Eighteenth Brumaire of Louis Bonaparte. In: TUCKER, R. C. (ed.).The Marx-Engels Reader. New York, W.W. Norton \& Company. 436-525, 1972.

NAZLOBU. Hugo Chávez: Agora Temos Kalashnikov! (27 jul. 2006). (Уго Чавес "Теперь у нас есть "Калашников"!) http://www.nazlobu.ru/opinions/print565. $\underline{\mathrm{htm}}$

PEOPLES. Chávez é o último bastião do socialismo (13 set. 2006). (Чавеcпоследний оплот социализма.) http://peoples.ru/state/king/venezuela/Chávez/ forum.shtml

PEW RESEARCH. Hugo Chávez: president for life or fading power?" (24 fev. 2009): http://pundit.co.nz/content/hugo-chavez-president-for-life-or-fading-power. 
POLITICHESKII JURNAL (Revista Política). A revolução no poder, n. 45 (48), 6 dez. 2004. (Революция у власти Политический журнал Архив): http://www. politjournal.ru/index.php? action $=$ Articles $\&$ dirid $=72 \&$ tek $=2668 \& i s s u e=81$

PORTIAKOVA, N. Hugo Chávez vê George Bush em Barak Obama".

Kommersant, 2 mar. 2005. (Наталия Портякова. Уго Чавес разглядел в Бараке Обаме Джорджа Буша. Коммерсантъ, 2 марта 2009. http://www.kommersant.ru/ doc.aspx? DocsID=1128286\&ThemesID=368)

PROKHANOV, A. Pátria ou Morte. Zavtra, n. 51 (578), 15 fev. 2004. (Александр Проханов, Родина или смерть.): http://www.zavtra.ru/cgi//veil//data/ zavtra/04/578/11.html

PUTIN, V. Russia is Europe's natural ally. Editorial em: The Sunday Times (GB), 25 mar. 2007.

REUTERS. What's in an Obama-Chávez handshake? (20 abr. 2009): http:// uk.reuters.com/article/idUKTRE53J6EK20090420.

SHIFTER, M. In search of Hugo Chávez. Foreign Affairs, maio/jun. 2006.

TRINKUNAS, H. A. Crafting civilian control of the military in Venezuela; A comparative perspective. Chapel Hill: University of North Carolina Press, 2005.

TSUNSKII, A. Hugo Chávez e Novas Esperanças de Moscou. Politeconomy (Андрей Цунский, Уго Чавес и новые надежды Москвы.): http://politeconomy. ng.ru/tek/2001-05-22/4_hopes.html

WILPERT, G. Changing Venezuela by Taking Power; the history and policies of the Chávez government. London: Verso, 2007. 